\title{
PENGARUH KONSENTRASI NATRIUM BENZOAT DAN LAMA PENYIMPANAN TERHADAP MUTU MINUMAN SARI BUAH GANDARIA (Bouea macrophylla Griff) BERKARBONASI
}

\author{
Rence Aurelia Sumanik ${ }^{1}$, P. M. Papilaya ${ }^{2}$, D. Rumahlatu ${ }^{2}$ \\ ${ }^{1}$ Alumni Program Studi Pendidikan Biologi \\ ${ }^{2}$ Dosen Program Studi Pendidikan Biologi \\ E-mail: joyfullpamela@yahoo.co.id
}

\begin{abstract}
Background: Gandaria plants (Bouea macrophylla Griff) are one of the annual Maluku fruits which need to be cultivated because they are beneficial both economically and ecologically. This study aims to determine the effect of sodium benzoate concentration and storage time on Gandaria fruit juice (Bouea macrophylla Griff).

Method: The type of research used in this study was an experimental type laboratory with experiments conducted in a closed room. This study uses ripe gandaria fruit in orange. This study used a completely randomized design method with 2 factors, namely, the concentration of sodium benzoate 200 ppm, 250 ppm, 300 ppm and storage time of 5 days, 10 days and 15 days. The parameters measured were vitamin C levels, total solid soluble and total acid levels.

Results: The study showed that the concentration of sodium benzoate and storage time had an effect on vitamin C, total acid and total soluble solid. Whereas the interaction between the concentration of sodium benzoate and the length of storage gave a significant effect on total acid.

Conclusion: The concentration of sodium benzoate and storage time have an effect on vitamin C, total acid and total soluble solid and the interaction between sodium benzoate concentration and storage time has a significant effect on total acid.
\end{abstract}

Keywords: Bouea macrophylla Griff, Sodium benzoate concentration, strorage time.

\begin{abstract}
Abstrak
Latar Belakang: Tanaman Gandaria (Bouea macrophylla Griff) merupakan salah satu tanaman buahan tahunan khas Maluku yang perlu dibudidayakan karena bermanfaat baik secara ekonomis maupun ekologis. Penelitian ini bertujuan untuk mengetahui pengaruh konsentrasi natrium benzoat dan lama penyimpanan terhadap sari buah Gandaria (Bouea macrophylla Griff).

Metode: Tipe penelitian yang digunakan dalam penelitian ini adalah tipe eksperimental laboratorium dengan percobaan dilakukan di dalam ruangan tertutup. Penelitian ini menggunakan buah gandaria yang telah masak berwarna orange. Penelitian ini menggunakan metode rancangan acak lengkap dengan 2 faktor yaitu, konsentrasi natrium benzoat 200 ppm, 250 ppm, 300 ppm dan lama penyimpanan 5 hari, 10 hari dan 15 hari. Parameter yang diukur adalah kadar vitamin $\mathrm{C}$, total soluble solid dan kadar total asam.

Hasil: Penelitian menunjukkan bahwa konsentrasi natrium benzoat dan lama penyimpanan memberikan pengaruh terhadap vitamin C, total asam dan total soluble solid. Sedangkan interaksi antara konsentrasi natrium benzoat dan lama penyimpanan memberikan pengaruh yang nyata terhadap total asam.

Kesimpulan: Konsentrasi natrium benzoat dan lama penyimpanan memberikan pengaruh terhadap vitamin C, total asam dan total soluble solid serta interaksi antara konsentrasi natrium benzoat dan lama penyimpanan memberikan pengaruh yang nyata terhadap total asam.
\end{abstract}

Kata Kunci: Bouea macrophylla Griff, Konsentrasi Natrium Benzoat, Lama Penyimpanan 


\section{PENDAHULUAN}

Tanaman gandaria (Bouea macrophylla Griff) merupakan salah satu tanaman buahan tahunan khas Maluku yang perlu dibudidayakan karena bermanfaat baik secara ekonomis maupun ekologis. Gandaria merupakan tanaman buah tropik Maluku yang sangat spesifik dan dikenal sebagai exotic fruit (Rehatta, 2005). Buah gandaria yang masih muda berwarna hijau dan dikonsumsi sebagai campuran sambal, rujak dan lalap (Sinay, 2011). Dapat digunakan sebagai pengganti jeruk nipis, asam dan asinan. Buah yang sudah matang berwarna kuning dan memiliki rasa kecut manis dapat dikonsumsi langsung sebagai buah meja, sebagai sari buah (es buah) maupun dalam bentuk olahan, seperti: sirup, manisan dan selai. Daun muda dapaat dimakan sebagai lalapan (Kurniawan \& Bayu, 2010). Kayunya dapat digunakan sebagai papan, bahan bangunan dan pegangan parang/keris karena tidak mudah pecah bila dikeringkan (Kurniawan \& Bayu, 2010). Selain itu, tanaman gandaria dapat dijadikan sebagai tanaman konservasi karena bentuk tajuk yang rimbun dan kompak dan sistem perakaran yang berkembang baik dan kuat untuk mencegah erosi (Tangkuman, 2006).

Tanaman gandaria berasal dari Asia Tenggara dan saat ini tersebar mulai dari Indonesia, Malaysia dan Amerika yang beriklim tropis. Penyebaran tanaman gandaria di Maluku, umumnya di pulau Ambon dan Saparua. Di pulau Ambon, tanaman gandaria tersebar di daerah pesisir pantai hingga perbukitan (Tangkuman, 2006). Di pulau Ambon, tanaman gandaria biasanya tumbuh di sekitar rumah dan di kebun (Papilaya, 2007). Daerah-daerah di pulau Ambon yang terdapat di daerah perbuktitan yang sesuai berdasarkan syarat tumbuh tanaman gandaria, yaitu Dusun Kusu-kusu, Kecamatan Nusaniwe, Kota Ambon yang merupakan daerah pertanaman buah yang sangat potensial. Gandaria merupakan salah satu pohon yang mendominasi di hutan daerah tangkapan air, sangat bermanfaat untuk menyimpan air dan melindungi daerah sekitar tangkapan air dari bahaya banjir dan erosi (Papilaya, 2002).
Minuman ringan (soft drink) adalah minuman yang tidak mengandung alkohol, merupakan minuman olahan dalam bentuk bubur atau cair yang mengandung bahan makanan atau bahan tambahan lainnya baik alami maupun sintetik yang dikemas dalam kemasan siap untuk dikonsumsi. Minuman ringan terdiri atas dua jenis, yaitu: minuman ringan dengan karbonasi (carbonated soft drink) dan minuman ringan tanpa karbonasi. Komposisi minuman ringan umumnya terdiri dari $90 \%$ air dan sisanya merupakan kombinasi pemanis buatan, gas $\mathrm{CO}_{2}$, cita rasa, pewarna asam fosfat, kafein dan beberapa mineral, terutama aluminium. Hal yang hanya ada pada minuman ringan adalah rasanya yang manis dan efeknya yang menyegarkan (Suyetmi Zentimer, 2007). Penggunaan gas $\mathrm{CO}_{2}$ dari tabung kurang praktis bagi industri rumah tangga dan mikro, namun praktis bagi skala yang lebih besar. Penambahan $\mathrm{CO}_{2}$ pada skala rumah tangga dan mikro dapat dilakukan dengan menambahkan soda kue $\left(\mathrm{NaHCO}_{3}\right)$. Soda kue dalam air akan membebaskan $\mathrm{CO}_{2}$ yang akan terserap dalam air atau sari buah jika setelah soda kue dimasukkan, dilakukan penutupan dengan rapat (Suyetmi Zentimer, 2007).

Penggunaan bahan tambahan atau zat aditif pada makanan semakin meningkat, terutama setelah adanya penemuanpenemuan termasuk keberhasilan dalam mensintesis bahan kimia baru yang lebih praktis, lebih murah, dan lebih mudah diperoleh. Penambahan bahan tambahan/zat aditif dalam makanan merupakan hal yang dipandang perlu untuk meningkatkan mutu suatu produk sehingga mampu bersaing di pasaran (Siaka, 2009). Batas atas benzoat yang diijinkan dalam makanan $0,1 \%$ di Amerika Serikat, sedangkan untuk negara-negara lain berkisar antara 0,15-0,25\%, dan negara Eropa batas benzoat berkisar antara 0,015$0,5 \%$ (lbekwe et al., 2007). Menurut Tisnawati (2005) bahwa penambahan bahan kimia (asam benzoat atau sodium benzoat) dalam larutan cenderung dapat memperpanjang masa simpan dan kesegaran bahan pangan dan tidak berpengaruh terhadap kesehatan manusia. 


\section{MATERI DAN METODE}

Penelitian ini dilaksanakan di Laboratorium Kimia Dasar Universitas Pattimura Ambon. Penelitian ini dilaksanakan dari bulan April sampai Juli 2016. Tipe penelitian yang digunakan adalah tipe eksperimental laboratorium dengan percobaan dilakukan di dalam ruangan terkait dengan pengaruh konsentrasi natrium benzoat dan lama penyimpanan terhadap minuman sari buah gandaria berkarbonasi.

Alat yang digunakan dalam penelitian ini adalah Hand refractometer, Termometer, Corong, Kertas saring, Gelas ukur, Gelas Erlenmeyer, Kertas label, Lemari pendingin, Buiret, Botol kaca, Beaker glass dan Pipet tetes. Sedangkan bahan yang digunakan dalam penelitian ini adalah Buah gandaria yang telah matang, Gula pasir, Garam dapur, Natrium benzoat, Natrium bikarbonat, Asam asetat, Phenolphthalein, $\mathrm{NaOH}$, Pati dan lodine.

Parameter yang diukur adalah kadar vitamin $\mathrm{C}$, kadar total gula dan total soluble solid. Penelitian ini menggunakan Rancangan Acak Lengkap (RAL) faktorial yang terdiri dari 2 faktor dengan 3 kali ulangan (Suyetmi, 2007) yaitu:

1. Faktor konsentrasi natrium benzoat $(\mathrm{K})$ terdiri dari 3 taraf :

$$
\begin{aligned}
& \mathrm{K}_{1}=200 \mathrm{ppm} \\
& \mathrm{K}_{2}=250 \mathrm{ppm} \\
& \mathrm{K}_{3}=300 \mathrm{ppm}
\end{aligned}
$$

2. Faktor lama penyimpanan yang terdiri dari 3 taraf :

$$
\begin{aligned}
& L_{1}=5 \text { hari } \\
& L_{2}=10 \text { hari } \\
& L_{3}=15 \text { hari }
\end{aligned}
$$

Di dalam pelaksanaan penelitian ini dilakukan tahap-tahap pembuatan sari buah gandaria sebagai berikut: Buah gandaria dicuci dengan air mengalir hingga bersih, Buah gandaria kemudian diblansing uap dengan asam asetat $0,05 \mathrm{~N}$ selama 10 menit, Buah gandaria dikupas dan dibuang bijinya. Kemudian daging buah gandaria dihancurkan dengan menggunakan blender dan ditambahkan air sebanyak 1:1 sehingga dihasilkan bubur buah, Bubur buah kemudian disaring sehingga diperoleh sari buah murni, sedangkan ampasnya dibuang, Sari buah gandaria kemudian ditambahkan gula pasir $22 \%$, garam dapur $0,30 \%$, natrium benzoat sesuai dengan masing perlakuan. Campuran kemudian diaduk sampai rata hingga menjadi homogeni (homogenasi). Sari buah gandaria yang sudah homogen dimasukkan dalam botol kemudian didinginkan dengan air es hingga dingin dalam keadaan botol tertutup rapat, Kemudian kedalam botol berisi sari gandaria ditambahkan $\mathrm{NaCO}_{3}$ $0,30 \%$ dan ditutup rapat sesegera mungkin (karbonasi), Botol yang sudah tertutup rapat dikocok dengan tujuan melarutkan $\mathrm{NaCO}_{3}$, Kemudian disimpan dalam lemari pendingin dan dianalisis sesuai dengan parameter pada penyimpanan 5 hari, 10 hari, 15 hari (Suyetmi, 2007). Data hasil penelitian selanjutnya dianalisis dengan menggunakan analisis ragam sesuai dengan rancangan acak lengkap yang digunakan, kemudian dilanjutkan dengan uji LSD (Suyetmi, 2007).

\section{HASIL DAN PEMBAHASAN}

Berdasarkan penelitian yang telah dilakukan maka pengaruh konsentrasi natrium benzoat dan lama penyimpanan terhadap kadar vitamin $\mathrm{C}$ berikut. 
Biopendix, Volume 4, Nomor 1, Oktober 2017, hlm. 22-28

Tabel 1. Konsentrasi Natrium Benzoat dan Lama Penyimpanan Terhadap Kadar Vitamin C

\begin{tabular}{cccccc}
\hline Sumber Keragaman & Jumlah Kuadrat & Df & $\begin{array}{c}\text { Rata-Rata } \\
\text { Kuadrat }\end{array}$ & $\mathbf{F}_{\text {hit }}$ & Sig \\
\hline Kombinasi KB & $7.703 \mathrm{E}-5^{\mathrm{a}}$ & 8 & $9.629 \mathrm{E}-6$ & $\begin{array}{c}10.5 \\
13\end{array}$ & .000 \\
\hline Konsentrasi natrium benzoat & $6.678 \mathrm{E}-5$ & 2 & $3.339 \mathrm{E}-5$ & $\begin{array}{c}36.4 \\
53\end{array}$ & .000 \\
\hline Lama penyimpanan & $9.050 \mathrm{E}-6$ & 2 & $4.525 \mathrm{E}-6$ & $\begin{array}{c}4.94 \\
0\end{array}$ & .019 \\
\hline Interaksi & $1.204 \mathrm{E}-6$ & 4 & $3.009 \mathrm{E}-7$ & .329 & .855 \\
\hline Galat & $1.649 \mathrm{E}-5$ & 18 & $9.159 \mathrm{E}-7$ & & \\
\hline Total & .004 & 27 & & & \\
\hline Total & $9.352 \mathrm{E}-5$ & 26 & & & \\
\hline
\end{tabular}

Hasil analisis varians pada Tabel 1 di atas menunjukkan bahwa nilai $F_{\text {hit }}$ variabel konsentrasi natrium benzoat ialah sebesar 36,453 dengan tingkat signifikansi 0,000 $(p=0,000<\alpha=0,05)$, artinya terdapat pengaruh konsentrasi natrium benzoat terhadap kadar vitamin C. Hasil analisis varians pada Tabel 1 di atas menunjukkan bahwa nilai $F_{\text {hit }}$ variabel lama penyimpanan ialah 4,940 dengan tingkat signifikansi $0,019,(p=0,019<\alpha=0,05)$, artinya terdapat pengaruh lama penyimpanan terhadap kadar vitamin C. Selanjutnya dilakukan uji LSD (Least Significance difference) dengan taraf kepercayaan $5 \%$ untuk menentukan perbedaan rata-rata kadar vitamin $\mathrm{C}$ dan kadar asam dari setiap konsentrasi natrium benzoat.

Tabel 2. Hasil Uji LSD Konsentrasi Natrium Benzoat Terhadap Kadar Vitamin C

\begin{tabular}{ccc}
\hline Konsentrasi & Rerata & Notasi \\
\hline $200 p p m$ & 0.01058 & $\mathrm{a}$ \\
\hline $250 \mathrm{ppm}$ & 0.01327 & $\mathrm{~b}$ \\
\hline $300 \mathrm{ppm}$ & 0.01432 & $\mathrm{c}$ \\
\hline
\end{tabular}

Tabel 3. Hasil Uji LSD Lama Penyimpanan Terhadap Kadar Asam

\begin{tabular}{ccc}
\hline Konsentasi & Rerata & Notasi \\
\hline 15 Hari & 0.011911 & $\mathrm{a}$ \\
\hline 10 hari & 0.01312 & $\mathrm{~b}$ \\
\hline 5 hari & 0.013155 & $\mathrm{~b}$ \\
\hline
\end{tabular}

Berdasarkan tabel 2 di atas diketahui bahwa adanya perbedaan notasi menunjukkan perbedaan yang sangat nyata pada masing-masing konsentrasi natrium benzoat terhadap kadar vitamin $\mathrm{C}$.

Berdasarkan hasil uji LSD pada Tabel 3 di atas diketahui bahwa lama penyimpanan 15 hari memiliki notasi a sedangkan notasi b pada lama penyimpanan 10 dan 5 hari. Hal ini menunjukkan bahwa lama penyimpanan 10 dan 5 hari tidak memiliki perbedaan yang nyata terhadap kadar vitamin C dan kadar asam, sedangkan kedua lama penyimpanan tersebut memiliki perbedaan yang sangat nyata dengan lama penyimpanan 15 hari kadar vitamin $\mathrm{C}$ dan kadar asam.

Menurut Winarno (2004), dari semua vitamin yang ada, vitamin C merupakan vitamin yang paling mudah rusak karena oksidasi terutama pada suhu tinggi dan merupakan vitamin yang mudah hilang selama penyimpanan dan pengolahan (Siregar, 2008). Kerusakan Vitamin C berhubungan dengan akitivitas enzim askorbat oksidase. Menurut Winarno 
(2004), asam askorbat mudah sekali teroksidasi menjadi asam Ldehidroaskorbat yang secara kimia sangat labil dan mengalami perubahan-perubahan

lebih lanjut menjadi asam L-ketogulonat dimana tidak memiliki keaktifan vitamin C lagi.

Tabel 4. Konsentrasi Natrium Benzoat dan Lama Penyimpanan Terhadap Kadar Asam

\begin{tabular}{cccccc}
\hline $\begin{array}{c}\text { Sumber } \\
\text { Keragaman }\end{array}$ & $\begin{array}{c}\text { Jumlah } \\
\text { Kuadrat }\end{array}$ & Df & $\begin{array}{c}\text { Rata-Rata } \\
\text { Kuadrat }\end{array}$ & $\mathbf{F}_{\text {hit }}$ & Sig \\
\hline Kombinasi KB & $.012^{\mathrm{a}}$ & 8 & .002 & 7.172 & .000 \\
\hline $\begin{array}{c}\text { Konsentrasi } \\
\text { natrium } \\
\text { benzoat }\end{array}$ & 64.536 & 1 & 64.536 & $3.076 \mathrm{E} 5$ & .000 \\
\hline $\begin{array}{c}\text { Lama } \\
\text { penyimpanana }\end{array}$ & .004 & 2 & .002 & 9.734 & .001 \\
\hline Interaksi & .003 & 2 & .001 & 6.757 & .006 \\
\hline Galat & .005 & 4 & .001 & 6.098 & .003 \\
\hline Total & .004 & 18 & .000 & & \\
\hline Total & 64.551 & 27 & & & \\
\hline
\end{tabular}

Berdasarkan tabel 4 di atas menunjukkan bahwa nilai $F_{\text {hit }}$ variabel konsentrasi natrium benzoat ialah sebesar 9,734 dengan tingkat signifikansi 0,001 $(p=0,001<\alpha=0,05), \quad$ artinya terdapat pengaruh konsentrasi natrium benzoat terhadap kadar asam. Hasil analisis varians pada tabel 4 di atas menunjukkan bahwa nilai $F_{\text {hit }}$ variabel lama penyimpanan ialah 6,757 dengan tingkat signifikansi 0,006, $(p=0,006<\alpha=0,05)$, artinya terdapat pengaruh lama penyimpanan terhadap kadar asam.

\section{Tabel 5. Hasil Uji LSD Konsentrasi Natrium Benzoat Terhadap Kadar Asam}

\begin{tabular}{ccc}
\hline Konsentrasi & Rerata & Notasi \\
\hline $300 \mathrm{ppm}$ & 1.5287 & $\mathrm{a}$ \\
\hline $200 \mathrm{ppm}$ & 1.5538 & $\mathrm{~b}$ \\
\hline $250 \mathrm{ppm}$ & 1.5556 & $\mathrm{~b}$ \\
\hline
\end{tabular}

Tabel 5 di atas diketahui bahwa kadar 300 ppm memiliki notasi a sedangkan notasi b pada kadar 200 ppm dan 250 ppm. Hal ini menunjukkan bahwa konsentrasi 200 ppm dan 250 ppm tidak memiliki perbedaan yang nyata terhadap kadar asam, sedangkan kedua konsentrasi tersebut memiliki perbedaan yang sangat nyata dengan konsentrasi 300 ppm terhadap kadar asam.

Tabel 7. Hasil Uji LSD Lama Penyimpanan Terhadap Kadar Asam

\begin{tabular}{ccc}
\hline Konsentasi & Rerata & Notasi \\
\hline 15 Hari & 1.5317 & $\mathrm{a}$ \\
\hline 10 hari & 1.5512 & $\mathrm{~b}$ \\
\hline 5 hari & 1.5552 & $\mathrm{~b}$ \\
\hline
\end{tabular}

Berdasarkan hasil uji LSD pada Tabel 6 di atas diketahui bahwa lama penyimpanan 15 hari memiliki notasi a sedangkan notasi b pada lama penyimpanan 10 dan 5 hari. Hal ini menunjukkan bahwa lama penyimpanan 10 dan 5 hari tidak memiliki perbedaan yang nyata terhadap kadar vitamin C dan kadar asam, sedangkan kedua lama penyimpanan tersebut memiliki perbedaan yang sangat nyata dengan lama 
penyimpanan 15 hari kadar vitamin $\mathrm{C}$ dan kadar asam. Berdasarkan hasil analisis varians pada (tabel 3) menunjukkan bahwa terdapat pengaruh konsentrasi natrium benzoat dan lama penyimpanan serta adanya interaksi antara konsentrasi natrium benzoat dan lama penyimpanan. maka Semakin tinggi konsentrasi natrium benzoat maka total asam sari buah gandaria dapat dipertahankan. Daya efektifitas dalam menghambat pertumbuhan mikroba salah satunya dipengaruhi oleh konsentrasi bahan pengawet yang digunakan. Semakin tinggi konsentrasi natrium benzoat maka efektifitas semakin meningkat sehingga selsel mikroba yang terdapat dalam bahan pangan akan semakin banyak yang rusak.

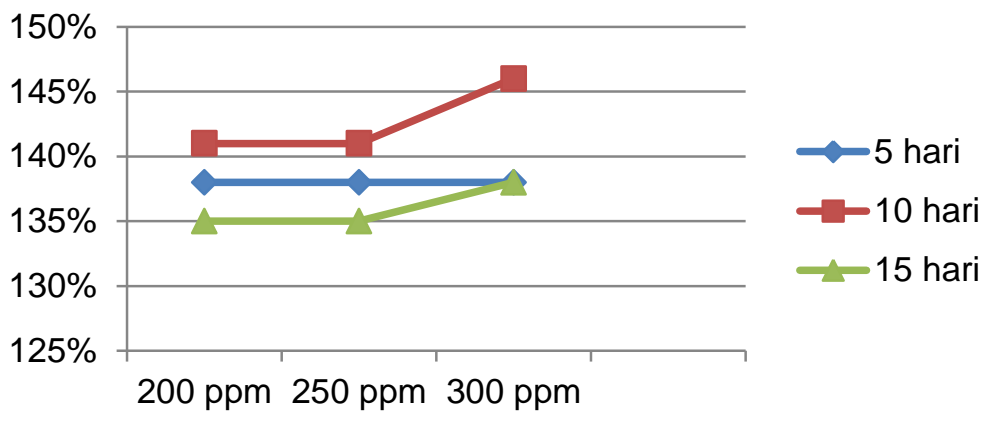

\section{Gambar 1. Grafik Hubungan Antara Konsentrasi Natrium Benzoat Dan Lama Penyimpanan Terhadap Mutu Minuman Sari Buah Gandaria.}

Berdasarkan grafik diatas menyatakan bahwa pemberian natrium benzoat dan lama penyimpanan tertinggi terdapat pada K3L2 dengan nilai sebesar $146 \%$ sedangkan terendah terpadat pada K1L3 dan K2L3 dengan nilai sebesar 135\%. Berdasarkan hasil penelitian yang dilakukan ditunjukkan bahwa kandungan Total Solible Solid minuman sari buah gandaria mengalami penurunan sejalan semakin lama penyimpanan. Sesuai perlakuan dengan konsentrasi natrium benzoate dan lama penyimpanan yang berbeda ditemukan bahwa total soluble solid tertinggi terdapat pada konsentarsi natrium benzoat 300 ppm dan lama penyimpanan 10 hari (K3L2) dengan nilai total soluble solid $146 \%$ dan mengalami penurunan pada konsentrasi natrium benzoat 300 ppm dan lama penyimpanan 15 hari (K3L3). Hal ini disebabkan karena akivitas mikroba dalam mendegradasi karbohidrat. Semakin lama penyimpanan maka semakin banyak karbohidrat yang didegradasi karena kesempatan mikroba untuk mendegradasi karbohidrat menjadi senyawa organic semakin besar sehingga total soluble solid yang terdapat pada minuman sari buah gandaria akan semakin menurun. Hal ini disebabkan pula oleh karena selama proses penyimpanan terjadi degradasi glukosa dan gula-gula sederhana menjadi senyawasenyawa yang lebih sederhana seperti asam-asam organik yang menyebabkan total soluble menjadi menurun (Zentimer, 2007).

\section{KESIMPULAN}

Berdasarkan hasil penelitian tersebut maka dapat disimpulkan bahwa konsentrasi natrium benzoat dan lama penyimpanan memberikan pengaruh terhadap vitamin $\mathrm{C}$, total asam dan total soluble solid. Sedangkan interaksi antara konsentrasi natrium benzoat dan lama penyimpanan memberikan pengaruh yang nyata terhadap total asam.

\section{DAFTAR PUSTAKA}

Harsono. T. 2012. Gandaria (Bouea macrophylla Griffith) Tumbhan Langkah Indonesia dan Flora Khas Jawa Barat. Sekolah Pasca Sarjana. Universitas sumatera Utara.

Ibekwe, Eberechukwu, S., Uwakwe, Amadikwa, A., \& Monanu, M. O. (2007). Effect of oral intake of sodium benzoate on some haematological parameters of wistar albino rats. 
Journal Scientific Research and Essay, 2(1), 6-9.

Kurniawan, M.B., \& P. Bayu. 2010. Mengenal Hewan Dan Flora Asli Indonesia. Cikal Aksara. Jakarta

Papilaya, P.M. 2007. Kajian Ekologi Gandaria (Bouea macrophylla Griffith). Hubungannya Dengan Produksi Dan Kualitas Buah Pada Ketinggian Dari Permikaan Laut Yang Berbeda Di Pulau Ambon. (Suatu Analisis Tentang Tumbuhan Endemik Daerah Maluku). [Disertasi]. Program Pascasarjana Universitas Negeri Malang.

Rehatta, H. 2005. Potensi Dan Pengembangan Tanaman Gandaria (Bouea macrophylla Griffith) Di Desa Soya Kecamatan Sirimau Kota Ambon. Lemlit Universitas Pattimura Ambon.

Siaka IM. 2009 Analisis Bahan Pengawet Benzoat Pada Saos Tomat Yang Beredar di Wilayah Kota Denpasar [Skrispsi]. Jurusan Kimia FMIPA Universitas Udiyana. Bukit Jimbaran.

Sinay, H. 2011. Pengaruh Giberalin Dan Temperatur Terhadap Pertumbuhan
Semai Gandaria (Bouea macrophylla Griffith). BIOSCIENTIAE 8:15- 22.

Siregar, R. 2008. Pengaruh Natrium Benzoat Dan lama Penyimpanan Terhadap Mutu Marmalade sirsak (Annona muricata $L$ ).

Suyetmi Zentimer. 2007. Pengaruh Konsentrasi Benzoat Dan Lama Penyimpanan Terhadap Mutu Minuman Sari Buah Sirsak (Annona muricata L) Berkarbonasi. [Skripsi]. Departemen Teknologi Pertanian. Fakultas Pertanian Universitas Sumatera Utara.

Tangkuman, C. 2006. Identifikasi Potensi Tanaman Gandaria (Bouea macrophylla Griff) Di Dusun Kusu-Kusu Sereh Desa Urimesing Kecamatan Nusaniwe Kota Ambon. [Skripsi]. Fakultas Pertanian Universitas Pattimura. Ambon.

Tisnawati. (2005). Tehnik penggunaan asam benzoat dan sodium benzoat untuk memperpanjang lama peragaan bunga sedap malam. Buletin Teknik Pertanian, 10(1).

Winarno, F.G. 1992. Kimia Pangan dan Gizi. Jakarta. Gramedia. 